\title{
Determinação da estrutura crustal para aprimorar os estudos de sismicidade na Região Sudeste do Brasil
}

Sabrina Pierobou*, Jesus Berrocal \& Celia Fernandes, Instituto de Astronomia, Geofísica e Ciências Atmosféricas IAG, Universidade de São Paulo, São Paulo, Brasil

Copyright 2004, SBGf - Sociedade Brasileira de Geofísica

Este texto foi preparado para a apresentação no I Simpósio Regional da Sociedade Brasileira de Geofísica, São Paulo, 26-28 de setembro de 2004. Seu conteúdo foi revisado pela Comissão Tecno-científica do I SR-SBGf mas não necessariamente representa a opinião da SBGf ou de seus associados. E proibida a reprodução total ou parcial deste material para propósitos comerciais sem prévia autorização da SBGf.

\section{Resumo}

Neste trabalho serão apresentados os resultados do levantamento de refração sísmica profunda (onde foram utilizados apenas tiros diretos e considerando um modelo de camadas planas) que está sendo efetuado na Região Sudeste e que nos permitirá definir o fator do tempo S-P com a distância. Também será possível com esse levantamento obter uma relação pontual da função de atenuação da energia sísmica na Região Sudeste. Será utilizado o método função do receptor para determinar a espessura crustal na região abaixo da Estação Sismográfica de Angra dos Reis, ESAR. Esses novos parâmetros nos permitirão obter um modelo mais preciso da estrutura crustal da Região Sudeste próxima a ESAR.

\section{Introdução}

Esta pesquisa tem por objetivo efetuar um estudo de refração sísmica profunda, que permita criar um modelo sísmico específico para a região, para aprimorar o estudo de sismos ocorridos na Região Sudeste do Brasil, tentando melhorar a localização epicentral.

A auscultação sismográfica da Região Sudeste é efetuada através de estações permanentes e também temporárias. Entre as estações permanentes estão as da RESUSP (Rede Sismográfica da Região Sudeste) desde 1996, de RSBC (Rede Sismográfica da Bacia de Campos) desde 1980 e também ESAR.

O estudo de refração sísmica profunda está sendo efetuado através de duas linhas, uma a nordeste de ESAR, de $20 \mathrm{~km}$ de extensão e a outra o sudoeste de ESAR, com cerca de $200 \mathrm{~km}$ (ver Fig. 1). A primeira linha, composta por seis estações sismográficas incluindo ESAR, utilizou como fonte de energia as explosões da pedreira de Lídice. A segunda linha, ainda em execução, é composta por treze estações, incluindo ESAR, e estão sendo utilizadas as explosões da Pedreira Embu S.A. em Mogi das Cruzes. Até o momento foram obtidos dados em apenas seis dos treze pontos de registro da linha mais extensa.

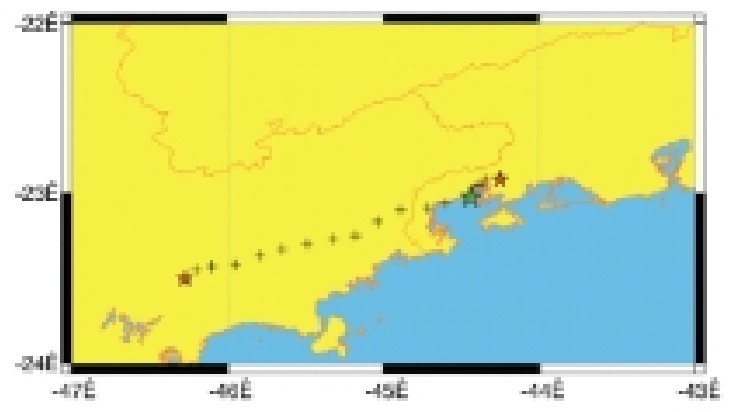

Fig. 1- Linhas de refração sísmica realizadas a NE e SE de ESAR (as explosões das pedreiras estão representadas pelas estrelas vermelhas, ESAR pela estrela verde e as cruzes são os pontos de registro).

As duas linhas têm apenas tiro direto devido a não existência de outras fontes de energia que permitam tiros reversos, entretanto isso não afeta o objetivo deste experimento que é principalmente determinar a função da distância com o tempo S-P. A linha mais curta, já concluída, é para definir esta função para distâncias locais, e a mais extensa para distâncias regionais.

A análise da linha de Lídice foi efetuada através do tempo de percurso das ondas $\mathrm{P}$ e $\mathrm{S}$, que permitiu a construção do gráfico caminho-tempo dessas ondas, onde foi possível detectar a existência de duas camadas com velocidades diferentes (ver Fig. 2). A primeira camada apresenta velocidade média aparente de 4,4 $\mathrm{km} / \mathrm{s}$ (Fig. 3), com $357 \mathrm{~m}$ de espessura calculada utilizando um valor de $t_{i}=0.11 \mathrm{~s}$ a segunda camada com velocidade média de $6,1 \mathrm{~km} / \mathrm{s}$ (Fig. 2), considerando-a horizontal, e indicando a presença de rochas metamórficas próximas da superfície, algumas delas aflorando nas proximidades de ESAR.

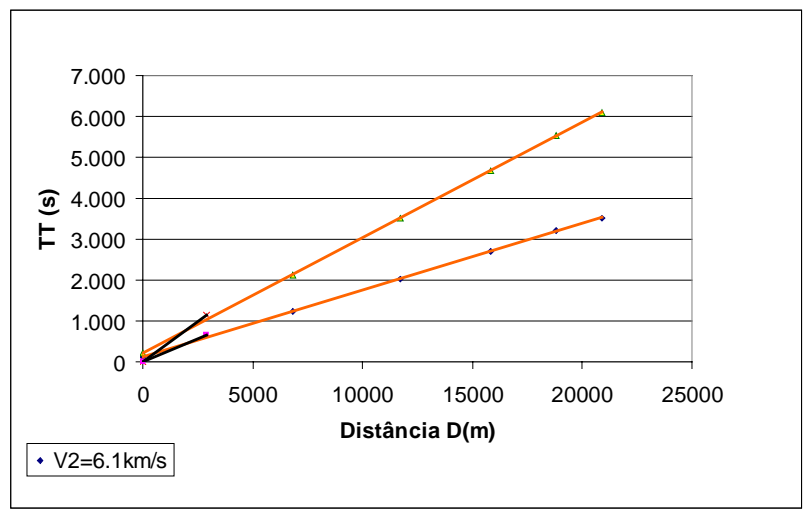

Fig. 2-Tempo de percurso para as ondas $P$ e $S$ nas proximidades de ESAR ( $<<20 \mathrm{~km})$. 


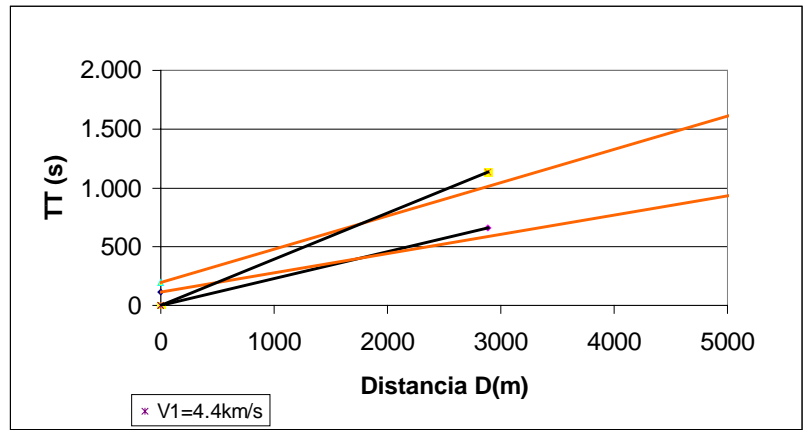

Fig. 3-Ampliação da Fig.2, mostrando o tempo de percurso para as ondas $\mathrm{P}$ e $\mathrm{S}$ nas proximidades de Lidice $(\mathrm{D}<5 \mathrm{~km})$.

Foram obtidas duas relações para o cálculo das distâncias dos eventos com base nos tempos S-P. A primeira equação: $\mathrm{D}=6.044(\mathrm{~S}-\mathrm{P})$ pode ser utilizada para tempos de S-P menores que 1 segundo. A segunda : $D=$ 8.37 (S-P) - 0.696 é utilizada para tempos maiores que 1 segundo e menores que 3 segundos, (para eventos próximos à ESAR), ambas as equações são mostradas na Fig.4. Esses dados permitirão a re-localização de eventos locais registrados em ESAR, com esses tempos de S-P.

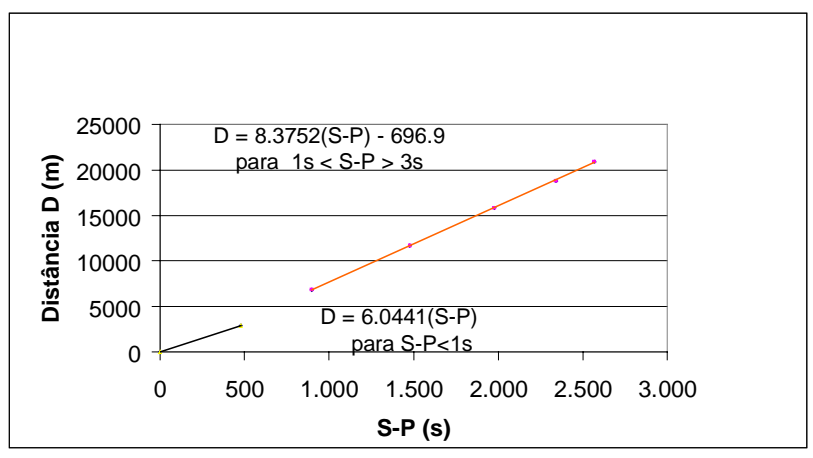

Fig. 4- Funções para cálculo de distancia com tempo S-P.

$\mathrm{Na}$ análise preliminar dos seis primeiros pontos de registro da linha de refração sísmica profunda, (ainda em andamento), pode ser verificada a existência de duas camadas com velocidades diferentes: uma com $5.8 \mathrm{~km} / \mathrm{s}$ e $4.4 \mathrm{~km}$ de espessura e outra com $6.4 \mathrm{~km} / \mathrm{s}$ (Fig. 5). Esses resultados concordam com o modelo obtido nesta região por Bassini(1986). A análise destes dados realizada através de tempo reduzido permitiu uma melhor visualização das duas camadas (Fig. 6) assim como encontrar o tempo de intersecção, usado para calcular a espessura da primeira camada. Um ponto registrado em ESAR, cuja distancia é de $193 \mathrm{~km}$ e 0.5 segundo de tempo reduzido, indica uma velocidade (para as camadas mais profundas) maior que 6.5 , o que já era esperado.

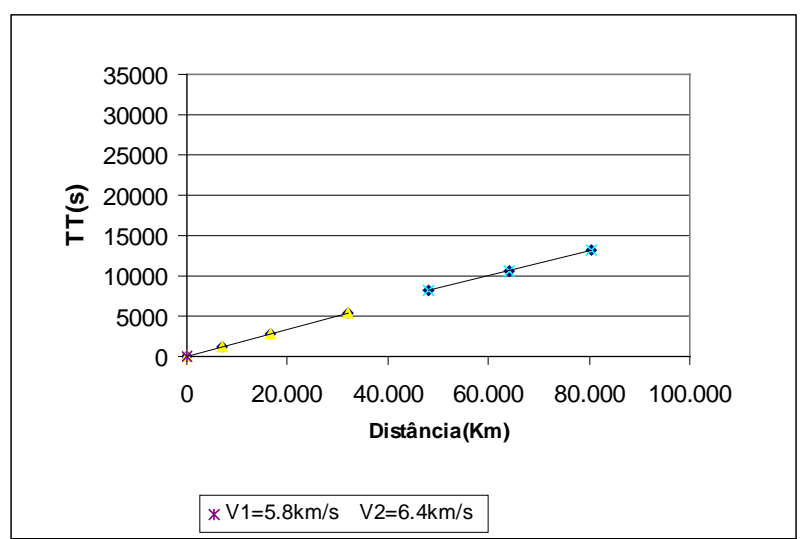

Fig. 5-Tempo de percurso para as ondas $\mathrm{P}$ e $\mathrm{S}$ para os primeiros $100 \mathrm{~km}$ da linha de refração sísmica profunda.

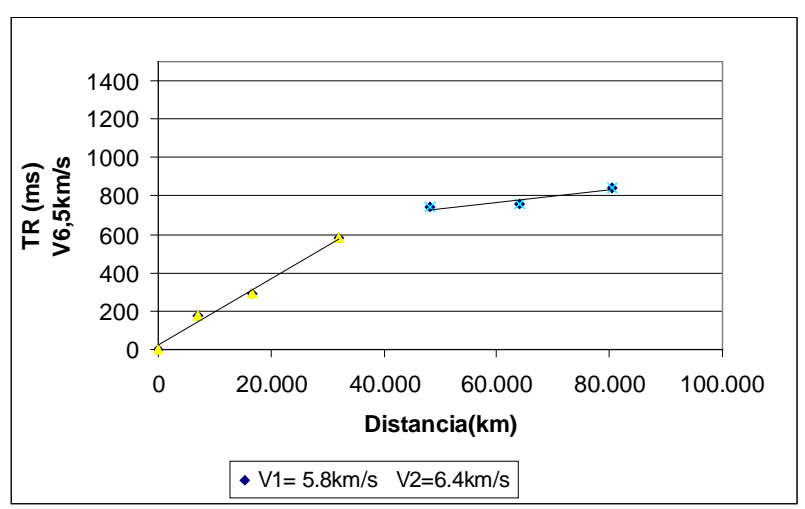

Fig. 6- Tempo reduzido com velocidade de $6.5 \mathrm{~km} / \mathrm{s}$, correspondente aos primeiros $100 \mathrm{~km}$ da linha.

Estamos iniciando a utilização do método de função do receptor para estimar a espessura da crosta terrestre sob ESAR, para poder comparar com resultados da linha mais extensa de refração sísmica. Para esta experiência preliminar foi selecionado o sismo de mb 6.4 ocorrido na região amazônica do Brasil em 20 de junho de 2003 com $556 \mathrm{~km}$ de profundidade e $30^{\circ}$ de distância epicentral, com relação à ESAR. Foi utilizado o procedimento e programa pwaveqn que está disponível no Laboratório de Sismologia do IAG/USP, e que são explicados com detalhe no trabalho de Costa (2004, apresentado neste simpósio). Foram testadas janelas de 100 e 30 segundos com dois valores de filtro gaussiano $(g=2$ e $g=5)$ para cada janela e o nível d'água foi mantido em 0,001. Os impulsos da Função do Receptor resultantes deste processamento são apresentados na Fig. 7. 


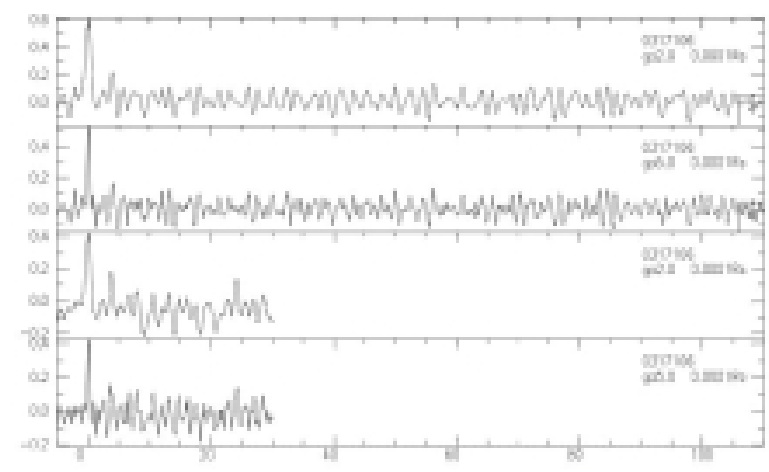

Fig. 7- Comparação dos dados de deconvolução, usando janelas diferentes (100 e 30s), sendo que para cada janela foram utilizados filtros gaussianos diferentes.

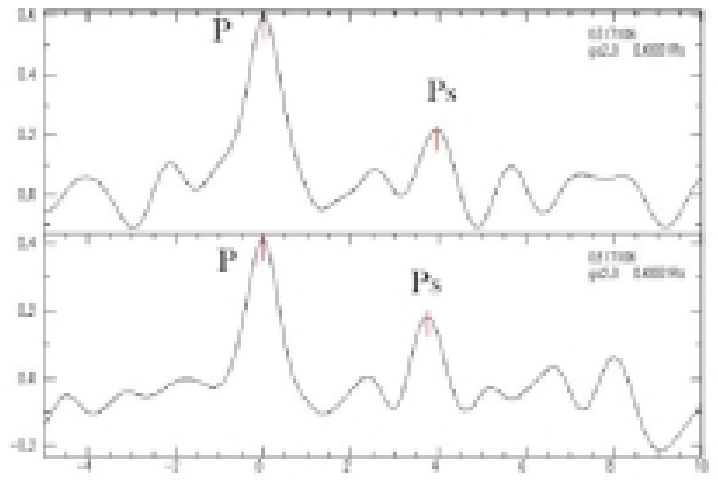

Fig. 8- Ampliação da Fig. 7, mostrando mais claramente os impulsos das ondas P e Ps. Leitura dos tempos de chegada das ondas P e Ps.

Os melhores resultados obtidos foram para as o filtro $\mathrm{g}=$ 2 que apresentam pulsos claros da fase Ps, que é mostrada na ampliação apresentada na Fig. 8, onde é possível ler a diferença de tempo entre esta fase e o impulso da onda P. Essa diferença foi utilizada para calcular a espessura crustal abaixo de ESAR. Foi utilizada velocidade média de $6.4 \mathrm{~km} / \mathrm{s}$ para a onda $P$ e uma razão $\mathrm{Vp} / \mathrm{Vs}=1.73$. Esses parâmetros resultaram numa espessura crustal sob ESAR de aproximadamente $31 \mathrm{~km}$, valor compatível com o obtido por França \& Assumpção, 2003.

\section{Referências:}

França, G.S., Estrutura da crosta do Sudeste e Centro Oeste do Brasil usando a Função do Receptor, Tese de Doutorado, Instituto de Astronomia Geofísica e Ciências Atmosféricas/USP São Paulo, SP, Brasil 82p.

Bassini, A. M., Levantamento Sismográfico na região Sudeste do Brasil, Dissertação de Mestrado IAG/USP, 1986.

Agradecimentos: Ficamos agradecido à ELETRONUCLEAR por auspiciar este projeto, assim como agradecemos à Luís Galhardo e Dennis Schramm (pai e filho) pelo esforço na aquisição de dados. Agradecemos também aos gerentes das pedreiras Embu S.A. e Lídice. 